\title{
Studying psychology is a neccessary way for aiding urban management and planning
}

\author{
Quang-Loc Nguyen \\ SP Jain School of Global Management \\ New South Wales, 2141, Australia \\ February 11, 2022
}

The majority of the population worldwide now lives in urban areas, thanks to urbanization processes. Addressing urban problems is important as it is set as a Goal 11 in Sustainable Development Goals (SDGs). Hillier et al. [1] point out that studying the geographic patterns of humans in built environments is necessary to get insights into how people interact within a city. The insights help urban planners to understand land-use trends in cities and urban inhabitants' responses to environmental changes, which aids the implementation of appropriate strategies and policies for building better working and living environments.

In the light of this, for example, there have been some attempts to investigate the psychological process in response to air pollution of urban citizens in my country [2,3]. Employing the Bayesian Mindsponge Framework [4-6], those studies suggest that people are highly likely to migrate to a better place due to the perceived cost of air pollution. In my opinion, findings from those studies can play a crucial role for the city council to consider the human-caused consequences, such as air pollution, to have rational approaches to improve living environments [7]. Otherwise, the city might lose its economic forces due to population relocation.

It can be said that even though investing in science might be costly, it is worthwhile for achieving the SDGs - better living standards [8].

Reference:

1. Hillier, B., Penn, A., Hanson, J., Grajewski, T. \& Xu, J. (1993). Natural movement: or, configuration and attraction in urban pedestrian movement. Environment and Planning B: planning and design, 20, 29-66.

2. Vuong, Q.H., Le, T.T., Nguyen, Q.L., Nguyen, Q.T. and Nguyen, M.H. (2021). Escaping from air pollution: The psychological process of domestic migration intention among urban people. OSF Preprints. Retrieved from: https://osf.io/5pv7y/

3. Vuong, Q.H., Le, T.T., Nguyen, Q.L., and Nguyen, M.H. (2021). Investigation into the rationale of migration intention due to air pollution integrating the Homo Oeconomicus traits. OSF Preprints. Retrieved from: https://osf.io/zxg83

4. Nguyen M.H, Le, T.T, Khuc VQ. (2021). Bayesian Mindsponge Framework. Scholarly Community Encyclopedia. Retrived from: https://encyclopedia.pub/13852

5. Vuong Q.H, Napier NK. (2015). Acculturation and global mindsponge: An emerging market perspective. International Journal of Intercultural Relations, 49, 354-367. 
6. Vuong, Q.H. (2016). Global mindset as the integration of emerging socio-cultural values through mindsponge processes: A transition economy perspective. In J.Kuada(Ed.), Global Mindsets: Exploration and Perspectives (pp.123-140). NewYork: Routledge

7. Vuong, Q.H. (2021). The semiconducting principle of monetary and environmental values exchange. Economics and Business Letters, 10(3), 284-290.

8. Vuong, Q.H. (2018). The (ir)rational consideration of the cost of science in transition economies. Nature Human Behaviour, 2, 5. 